\title{
Variability in the reported energy, total fat and saturated fat contents in fast-food products across ten countries
}

\author{
Nida Ziauddeen ${ }^{1}$, Emily Fitt ${ }^{1}$, Louise Edney ${ }^{1,2}$, Elizabeth Dunford ${ }^{3,4}$, Bruce Neal ${ }^{3,4}$ and \\ Susan A Jebb ${ }^{1,5, *}$ \\ ${ }^{1}$ MRC Human Nutrition Research, Elsie Widdowson Laboratory, Cambridge, UK: ${ }^{2}$ School of Sport, Exercise and \\ Health Sciences, Loughborough University, Loughborough, UK: ${ }^{3} T$ he George Institute for Global Health, \\ Camperdown, NSW, Australia: ${ }^{4}$ The University of Sydney and Royal Prince Alfred Hospital, Sydney, NSW, \\ Australia: ${ }^{5}$ Department of Primary Care Health Sciences, University of Oxford, Radcliffe Observatory Quarter, \\ Woodstock Road, Oxford OX2 6GG, UK
}

Submitted 27 February 2014: Final revision received 17 November 2014: Accepted 7 January 2015: First published online 23 February 2015

\begin{abstract}
Objective: Fast foods are often energy dense and offered in large serving sizes. Observational data have linked the consumption of fast foods to an increased risk of obesity and related diseases.

Design: We surveyed the reported energy, total fat and saturated fat contents, and serving sizes, of fast-food items from five major chains across ten countries, comparing product categories as well as specific food items available in most countries.

Setting: MRC Human Nutrition Research, Cambridge, UK.

Subjects: Data for 2961 food and drink products were collected, with most from Canada ( $n$ 550) and fewest from the United Arab Emirates ( $n$ 106).

Results: There was considerable variability in energy and fat contents of fast foods across countries, reflecting both the portfolio of products and serving size variability. Differences in total energy between countries were particularly noted for chicken dishes (649-1197 kJ/100 g) and sandwiches (552-1050 kJ/100 g). When comparing the same product between countries variations were consistently observed in total energy and fat contents ( $\mathrm{g} / 100 \mathrm{~g})$; for example, extreme variation in McDonald's Chicken McNuggets with $12 \mathrm{~g}$ total fat/100 g in Germany compared with $21 \cdot 1 \mathrm{~g} / 100 \mathrm{~g}$ in New Zealand.

Conclusions: These cross-country variations highlight the possibility for further product reformulation in many countries to reduce nutrients of concern and improve the nutritional profiles of fast-food products around the world. Standardisation of serving sizes towards the lower end of the range would also help to reduce the risk of overconsumption.
\end{abstract}

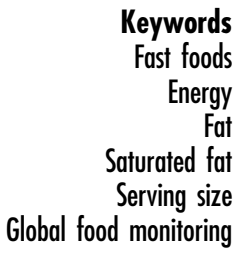

'Fast food' epitomises the change in food culture in Western countries over the last 60 years. More recently many of the most well-known quick-service chains have established themselves elsewhere, particularly in the Middle East and Asia-Pacific countries ${ }^{(1,2)}$.

These outlets have evolved to meet the needs of timepoor consumers, offering standardised food and/or drink items that can be served quickly, from pre-prepared or processed ingredients, with outlets sited to be readily accessible to large numbers of consumers ${ }^{(3-6)}$. However, the ecological associations between fast-food outlets and the prevalence of obesity have raised health concerns. In the UK the density of fast-food outlets is greatest in areas of deprivation which also have a higher prevalence of childhood obesity ${ }^{(7,8)}$ and in the USA there is a demonstrated correlation between proximity to fast-food outlets and obesity ${ }^{(9,10)}$. A review of the effects of fast foods in rural China has also shown a positive correlation between measures of obesity and the number of fast-food outlets $^{(11)}$. Other studies have related fast-food intake to weight gain and insulin resistance ${ }^{(12-16)}$, associations attributed to the energy density and high levels of fat, saturated fat, added sugar and salt in many fast-food items $^{(17)}$. Fast foods are often also offered in large serving sizes and up-selling is common both through promotions and at the point of sale ${ }^{(18)}$.

Although usually purporting to be standardised products, there are reports of significant differences in the nutritional content of apparently identical fast-food items provided by the same vendor. In 2005-2006, a comparison 
of the fat content of French fries and fried chicken from thirty-five countries showed a range of 41 to $65 \mathrm{~g} /$ serving at McDonald's and 42 to $74 \mathrm{~g} /$ serving at Kentucky Fried Chicken $(\mathrm{KFC})^{(19)}$. More recently, a survey showed variability in the nutrient content of fast foods from leading chain restaurants in Australia ${ }^{(20)}$ and marked variation in salt content per $100 \mathrm{~g}$ of the same product in different countries ${ }^{(21)}$. Moreover, there can be considerable variation in serving size that impacts on the absolute nutrient content per serving. For example, serving sizes are reported to be greater in the USA than for comparable outlets in Europe ${ }^{(22)}$.

In 2010 the Global Food Monitoring Group was established with the aim of collating and sharing product data between collaborating countries, enabling tracking of changes in product nutritional composition worldwide, including both retail sales and out-of-home purchases ${ }^{(23)}$. Given the popularity of fast-food products we explored the reported nutrient contents of comparable food items from popular transnational chains, to determine the extent of cross-country variation in energy $(\mathrm{kJ})$, total fat $(\mathrm{g})$ and saturated fat $(\mathrm{g})$ contents and to help guide the identification of better product formulation.

\section{Methods}

A survey of the reported energy (kJ), total fat (g) and saturated fat $(\mathrm{g})$ contents per serving and per $100 \mathrm{~g}$ in food and drink items was undertaken across ten countries: Canada, USA, Netherlands, UK, Germany, United Arab Emirates (UAE), Australia, New Zealand, China and Japan, with data collected for products where the descriptors implied they were broadly comparable by ingredients or product type. Data were collected between January and March 2012 from company websites. Serving size and total fat data for McDonald's Japan products were collected in November 2012 as this information was not previously available online and provided that the nutrient data online matched the information previously collected. A full outline of the data collection protocol for fast foods has been published previously ${ }^{(23)}$.

\section{Data collection}

A fast-food chain was defined as an outlet that sells food products that are ready-to-eat, sold in servings and not arriving in the outlet in their final package ${ }^{(23)}$. Data were obtained for all available food and drink products from fast-food chain websites specific to each country, using publically available product information, and entered into a data collection spreadsheet. Data for each food and drink item were collected by country, recording chain name, product title and serving size ( $\mathrm{g}$ and $\mathrm{ml}$ for drinks). The nutritional content recorded for each product was energy $(\mathrm{kJ} /$ serving and $\mathrm{kJ} / 100 \mathrm{~g})$, total fat ( $\mathrm{g} /$ serving and $\mathrm{g} / 100 \mathrm{~g}$ ) and saturated fat (g/serving and $\mathrm{g} / 100 \mathrm{~g})$. In instances where data were not provided per $100 \mathrm{~g}$ of product this was calculated based on the reported serving
Table 1 Fast-food categorisation system

\begin{tabular}{ll}
\hline $\begin{array}{l}\text { Fast-food } \\
\text { category }\end{array}$ & Description \\
\hline Breakfast items & $\begin{array}{c}\text { Morning menu items only served as breakfast, } \\
\text { including hash browns and muffins } \\
\text { Products consumed in the form of a burger, with } \\
\text { a bread bun, including vegetable/chicken/ } \\
\text { beef, excluding breakfast burgers } \\
\text { Chicken products including nuggets, drumsticks, } \\
\text { fried/grilled/roast chicken, excluding chicken } \\
\text { burgers } \\
\text { Chicken }\end{array}$ \\
All items described in the menu as pizza, with a \\
dough base and toppings \\
Sizza & $\begin{array}{c}\text { Salad-based items, including plain salad } \\
\text { vegetables and those containing meat } \\
\text { and/or pasta }\end{array}$ \\
Salads & $\begin{array}{c}\text { Filled breads and wraps excluding breakfast } \\
\text { menu items and burgers }\end{array}$ \\
Sides & $\begin{array}{c}\text { All items described as additional products to the } \\
\text { main food items, including fries/chips, onion } \\
\text { rings and corn }\end{array}$ \\
Beverages & $\begin{array}{c}\text { Fluid-based drinks, including milkshakes, thick } \\
\text { shakes, fruit and milk smoothies and other } \\
\text { milk-based drinks, excluding pure fruit juices, } \\
\text { carbonated soft drinks, water, tea, coffee and } \\
\text { hot chocolate }\end{array}$ \\
\hline
\end{tabular}

size weight. When energy content was provided only as $\mathrm{kcal}$, it was converted to $\mathrm{kJ}$ using the conversion factor $1 \mathrm{kcal}=4 \cdot 184 \mathrm{~kJ}$.

An attempt was made to collect information for all food and drink items displayed on chain websites, resulting in data for 2961 products. Where nutritional data or serving size information was not provided on the website, or if there was a technical fault with the website at the time of data collection, the relevant information was requested via email to customer services or the company nutritionist if known. A total of twenty emails were sent with three responses received in total. Data collected were subject to quality checks, with a random sample of $10 \%$ of all products double checked by a nutritionist for legitimacy and errors in transcription from the original data source. The Google Translate tool was used to assist in language translation where web pages were not provided in English.

\section{Product categories}

Food items were grouped into eight categories: (i) breakfast items; (ii) burgers; (iii) chicken products; (iv) pizza; (v) sides; (vi) salads; (vii) sandwiches; and (viii) milkshake-type beverages (Table 1). These product categories are consistent with previous published reports in this field ${ }^{(20,21)}$. Any products that were family share combinations marketed to serve more than one person, or combinations of products falling into multiple categories, such as meal deals, were excluded from this analysis.

\section{Data analysis}

The median nutrient content $(\mathrm{kJ}$ or $\mathrm{g} /$ serving and $\mathrm{kJ}$ or $\mathrm{g} / 100 \mathrm{~g}$ ), for each food category and country, were 
Table 2 Count $(n)$ of categorised fast-food products across selected countries; data collected from company websites in a survey of fastfood items from five major chains across ten countries, January-March 2012

\begin{tabular}{|c|c|c|c|c|c|c|c|c|c|c|}
\hline & Australia & Canada & China & Germany & Japan & Netherlands & New Zealand & UAE & UK & USA \\
\hline Beverages & 26 & 21 & 20 & 15 & 14 & 29 & 24 & 3 & 23 & 19 \\
\hline Breakfast items & 18 & 104 & 26 & 18 & 19 & 1 & 31 & 4 & 37 & 74 \\
\hline Burgers & 46 & 36 & 25 & 37 & 35 & 35 & 49 & 35 & 36 & 56 \\
\hline Chicken & 21 & 31 & 13 & 21 & 38 & 29 & 18 & 18 & 31 & 80 \\
\hline Pizza & 28 & 217 & * & * & 165 & * & 76 & * & 115 & 152 \\
\hline Salads & 11 & 33 & 6 & 20 & 35 & 8 & 17 & 14 & 35 & 31 \\
\hline Sandwiches & 60 & 64 & 28 & 32 & 37 & 25 & 60 & 18 & 65 & 81 \\
\hline Sides & 21 & 44 & 20 & 20 & 54 & 24 & 20 & 14 & 47 & 48 \\
\hline
\end{tabular}

UAE, United Arab Emirates.

*Data not available online or received following direct contact.

Table 3 Median serving sizes ( $\mathrm{g}$; $\mathrm{ml}$ for beverages) for fast-food products by category and country; data collected from company websites in a survey of fast-food items from five major chains across ten countries, January-March 2012

\begin{tabular}{|c|c|c|c|c|c|c|c|c|c|c|}
\hline & Australia & Canada & China & Germany & Japan & Netherlands & New Zealand & UAE & UK & USA \\
\hline Beverages & 383 & 375 & * & 281 & 295 & 351 & 370 & 434 & 401 & 375 \\
\hline Breakfast items & 143 & 149 & * & 116 & 133 & 131 & 146 & 144 & 140 & 147 \\
\hline Burgers & 221 & 196 & * & 204 & 186 & 232 & 225 & 263 & 218 & 211 \\
\hline Chicken & 115 & 92 & * & 180 & 162 & 183 & 90 & 102 & 84 & 83 \\
\hline Pizza & * & 752 & * & $*$ & 744 & * & * & * & * & 832 \\
\hline Salads & 364 & 291 & * & 327 & 172 & 205 & 323 & 260 & 286 & 308 \\
\hline Sandwiches & 215 & 219 & 224 & 218 & 175 & 224 & 213 & 220 & 242 & 202 \\
\hline Sides & 120 & 113 & * & 143 & 123 & 118 & 99 & 136 & 167 & 99 \\
\hline
\end{tabular}

UAE, United Arab Emirates.

${ }^{*}$ Data not available online or received following direct contact.

examined. Products were reviewed by title to ensure cross-country comparison of the same product. Of the 2961 products collected, ten food and drink products symbolising the brand as their signature product, or assumed by the authors as one of the most popular menu items, were directly compared at an individual level. Data were checked for distribution and medians and ranges were calculated using the statistical software package IBM SPSS Statistics version 21. Due to the nature of these data, statistical analysis was not appropriate; therefore descriptive data are presented only.

\section{Results}

Data on the reported energy $(\mathrm{kJ})$, total fat $(\mathrm{g})$ and saturated fat (g) contents of fast-food products ( $n$ 2961) were collected across ten countries for five fast-food chains: (i) Burger King (Hungry Jack's in Australia and New Zealand); (ii) KFC; (iii) McDonald's; (iv) Pizza Hut; and (v) Subway. The fewest number of products were collected for the UAE ( $n$ 106), with the greatest number from Canada ( $n 550$; Table 2 ). Pizza had the most products by category ( $n$ 753) whereas beverages had the fewest products ( $n$ 194).

\section{Serving size comparisons by country}

Across countries there was marked variation in the median serving size within product categories, with the lowest variation in breakfast items and the highest in salads
(Table 3). Japan had the lowest serving sizes for four product categories: burgers, pizza, salads and sandwiches. Two countries had the highest median serving sizes for two product categories each: UAE for beverages and burgers, and the UK for sandwiches and sides. Small variations were observed in serving sizes of breakfast items, burgers, pizza, sandwiches and sides across the ten countries, with the maximum within-category difference in median serving size being $88 \mathrm{~g}$ or less. However, beverages and salads showed particularly large variability. Beverages ranged from the lowest median serving size of $281 \mathrm{ml}$ in Germany to more than $50 \%$ greater in the UAE, which had the highest median serving size of $434 \mathrm{ml}$. Salads ranged from the smallest median serving at $172 \mathrm{~g}$ in Japan to more than twice this size in Australia where the median serving was $364 \mathrm{~g}$. Likewise, the median serving size for chicken in Germany was more than double that in the USA (180 $\mathrm{g}$ and $83 \mathrm{~g}$, respectively).

\section{Energy, total fat and saturated fat contents by country}

The salads category displayed the lowest variation in energy, total fat and saturated fat contents across countries and chicken the highest (Figs 1, 2 and 3). Chicken in the Netherlands offered the lowest energy density $(649 \mathrm{~kJ} /$ $100 \mathrm{~g})$ as compared with the USA which offered the highest (1196 kJ/100 g). Sides showed less variation, with Japan offering the lowest energy density ( $914 \mathrm{~kJ} / 100 \mathrm{~g})$ and Germany offering the highest (1238 kJ/100 g; Fig. 1). 


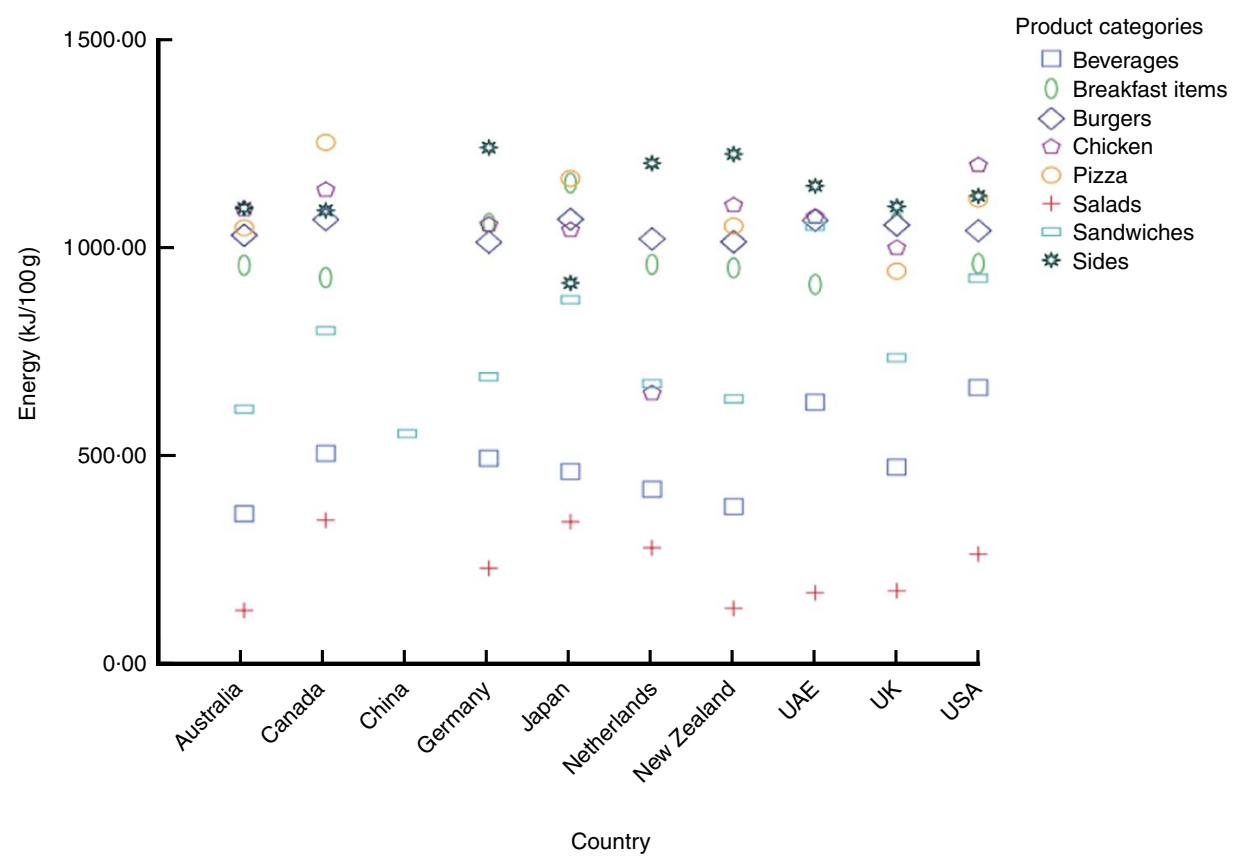

Fig. 1 (colour online) Median energy content (kJ/100 g; kJ/100 ml for beverages) of categorised fast-food products across selected countries; data collected from company websites in a survey of fast-food items from five major chains across ten countries, January-March 2012 (UAE, United Arab Emirates)

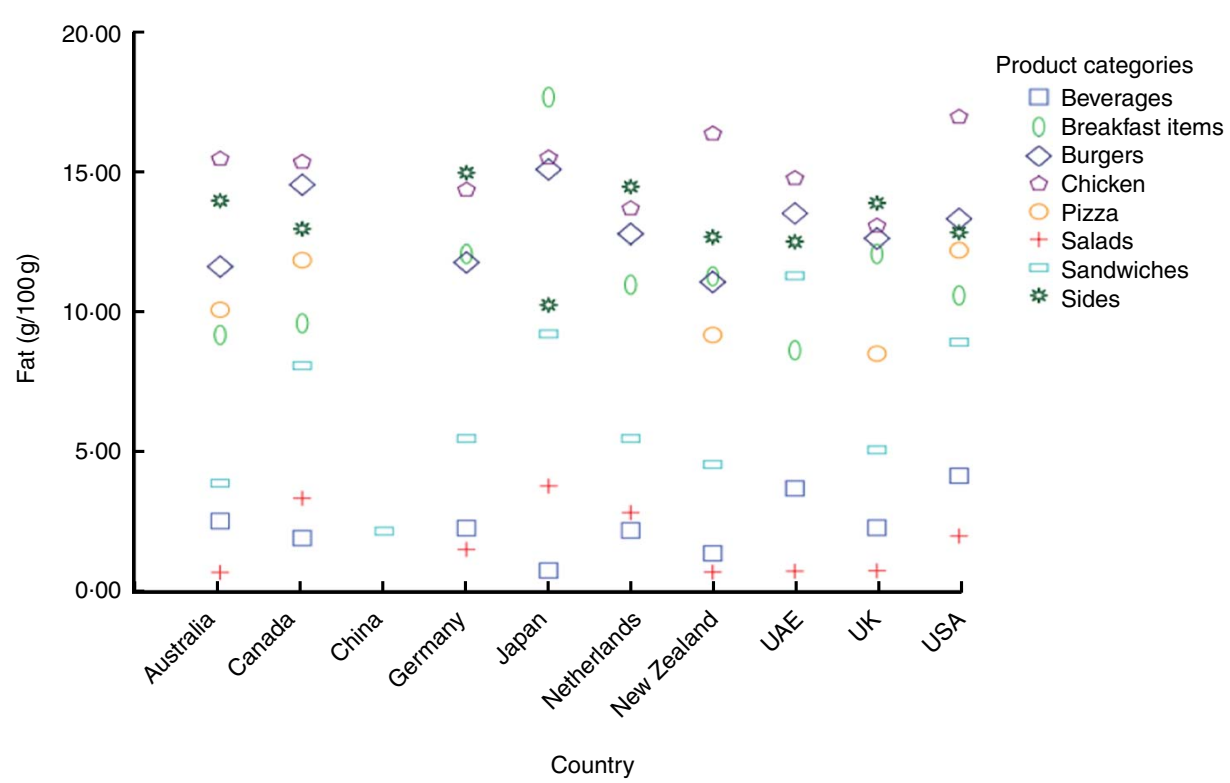

Fig. 2 (colour online) Median total fat content (g/100 g; g/100 ml for beverages) of categorised fast-food products across selected countries; data collected from company websites in a survey of fast-food items from five major chains across ten countries, January-March 2012 (UAE, United Arab Emirates)

The lowest median total fat content per $100 \mathrm{~g}$ (per $100 \mathrm{ml}$ for beverages) was observed in two categories each in Japan (beverages and sides), New Zealand (burgers and salads) and the UK (chicken and pizza); however, the highest median total fat per $100 \mathrm{~g}$ (per $100 \mathrm{ml}$ for beverages) was observed in three categories each in Japan (breakfast items, burgers and salads) and the USA (beverages, chicken and pizza; Fig. 2). Large variations were observed in total fat per $100 \mathrm{~g}$ for all countries especially in the breakfast items and sandwiches categories. Breakfast items available in Japan offered the highest total fat $(17.7 \mathrm{~g} / 100 \mathrm{~g})$ as compared with the UAE which offered the lowest $(8.6 \mathrm{~g} / 100 \mathrm{~g})$. Sandwiches in China contained the lowest median total and saturated fat per $100 \mathrm{~g}(2 \cdot 2 \mathrm{~g}$ and $0.8 \mathrm{~g})$ as compared with the UAE ( $11.3 \mathrm{~g}$ and $4.4 \mathrm{~g})$ reflecting differences in the menu items available. 


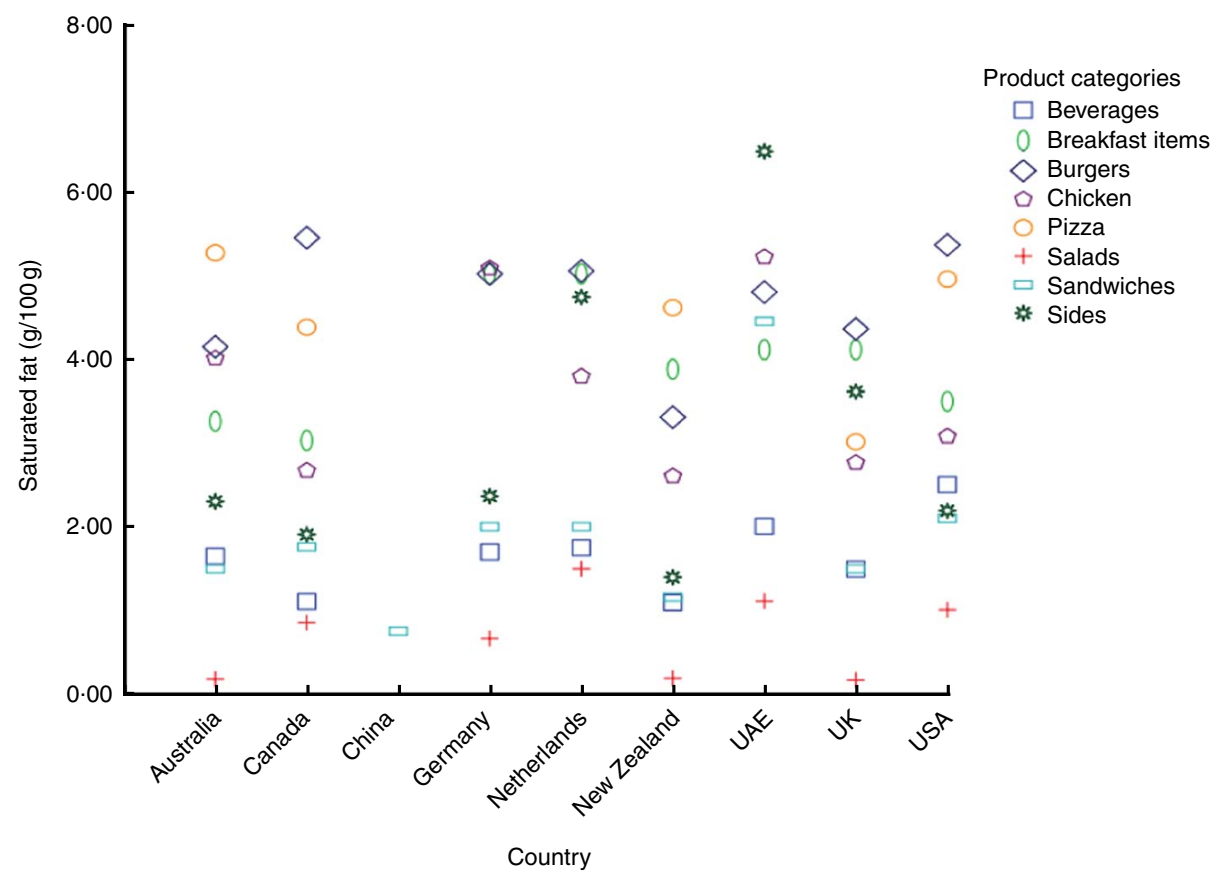

Fig. 3 (colour online) Median saturated fat content (g/100 g; g/100 ml for beverages) of categorised fast-food products across selected countries; data collected from company websites in a survey of fast-food items from five major chains across ten countries, January-March 2012 (UAE, United Arab Emirates)

New Zealand had the lowest saturated fat per $100 \mathrm{~g}$ (per $100 \mathrm{ml}$ for beverages) in five product categories (beverages, burgers, chicken, salads and sides), whereas the UAE had the highest in three product categories (chicken, sandwiches and sides).

\section{Energy, total fat and saturated fat contents per serving}

The median energy content per serving varied within all product categories, with differences ranging from $364 \mathrm{~kJ} /$ serving for sandwiches to $1581 \mathrm{~kJ} /$ serving for beverages (see online supplementary material, Supplemental Table 1). Chicken products in the USA and Germany had comparable median energy per $100 \mathrm{~g}$ (1197 kJ and $1054 \mathrm{~kJ}$, respectively) but the median serving size in Germany was more than double that in the USA (180 $\mathrm{g}$ and $83 \mathrm{~g}$, respectively). Consequently chicken in the USA demonstrated the lowest median energy content per serving $(1025 \mathrm{~kJ})$ and Germany the highest (2096 kJ). Median energy per serving for sandwiches and sides from the UK were the highest among all countries, $1741 \mathrm{~kJ}$ and $1582 \mathrm{~kJ}$ respectively, which is in line with the UK recording the largest mean serving sizes for these product categories (242 $\mathrm{g}$ and $167 \mathrm{~g}$ ).

A similar pattern was observed for total fat and saturated fat. Breakfast items available in China offered the highest median total fat $(24.0 \mathrm{~g})$ and saturated fat $(10.0 \mathrm{~g})$ contents per serving (see online supplementary material, Supplemental Tables 2 and 3) as compared with the UAE which offered the lowest total fat at $50 \%$ less than that of China $(12.0 \mathrm{~g} / \mathrm{serving})$. Canada had the lowest median saturated fat content per serving $(5.0 \mathrm{~g})$ for breakfast items. The total fat and saturated fat contents of beverages were greatest in Chinese products ( $18.5 \mathrm{~g} /$ serving and $13.5 \mathrm{~g} / \mathrm{serving})$, closely followed by the USA $(18.0 \mathrm{~g} /$ serving and $12.0 \mathrm{~g} /$ serving) and more than $50 \%$ higher than UK products (9.0 g/serving and $6.0 \mathrm{~g} /$ serving, respectively). The UK had the highest total fat content for sides ( $19.0 \mathrm{~g} / \mathrm{serving})$, which is $2 \cdot 8 \mathrm{~g} /$ serving more than the next ranked country (UAE) and $8.5 \mathrm{~g} /$ serving more than the lowest ranked country (USA). Despite this the UAE had the highest saturated fat per serving for sides $(7 \cdot 1 \mathrm{~g})$, which was $2 \cdot 1 \mathrm{~g} /$ serving higher than the UK.

\section{Specific product comparisons by country}

In order to control for differences in available menu items, we reviewed the reported total energy, fat and saturated fat contents $(\mathrm{g} / 100 \mathrm{~g})$ of ten individual products across five chains, which were comparable by product name and description in all selected countries (results for energy are presented in Table 4; results for fat and saturated fat are presented in the online supplementary material, Supplemental Tables 4 and 5). Total energy and fat contents per $100 \mathrm{~g}$ varied for each product between countries. Burger King's Whopper Burger showed the least variation (967-1029 kJ, 12.6-14.5 g) and KFC Original Recipe Chicken the most (536-1301 kJ, 7.5-18.2 g). McDonald's Chicken McNuggets showed extreme variation with $12.0 \mathrm{~g}$ total fat per $100 \mathrm{~g}$ in Germany as compared with $21.1 \mathrm{~g}$ in New Zealand. Although KFC Original Recipe Chicken showed high variation in energy content (536-1301 kJ/100 g), only some countries stated the type of 
Table 4 Reported total energy content $(\mathrm{kJ} / 100 \mathrm{~g})$ of comparable fast-food products, by country; data collected from company websites in a survey of fast-food items from five major chains across ten countries, January-March 2012

\begin{tabular}{|c|c|c|c|c|c|c|c|c|c|c|}
\hline & Australia & Canada & China & Germany & Japan & Netherlands & New Zealand & UAE & UK & USA \\
\hline \multicolumn{11}{|l|}{ Burger King } \\
\hline Cheeseburger & 1130 & 1013 & * & 1100 & 1105 & 1109 & 1105 & $\dagger$ & 1063 & 1033 \\
\hline Hamburger & 1084 & 979 & * & 1063 & 1063 & 1075 & 1071 & 1050 & 1025 & 996 \\
\hline Whopper & 1029 & 967 & * & 967 & 979 & 983 & 971 & 992 & 996 & 967 \\
\hline \multicolumn{11}{|l|}{ KFC } \\
\hline Original Recipe Chicken (1 piece) & 594 & 1188 & * & 536 & 1138 & 552 & 1100 & 1301 & * & 1088 \\
\hline \multicolumn{11}{|l|}{ McDonalds } \\
\hline Big Mac & 1025 & 1079 & * & 937 & 1033 & 937 & 1017 & 1021 & 958 & 1054 \\
\hline Chicken McNuggets (6 pieces) & 1180 & 1138 & * & 979 & 1172 & 979 & 1255 & 1067 & 996 & 1209 \\
\hline Garden Side Salad & 63 & 142 & * & 54 & 67 & 96 & 54 & 414 & 46 & 96 \\
\hline \multicolumn{11}{|l|}{ Pizza Hut } \\
\hline Cheese pizza (thin crust) & 1259 & 1326 & * & * & 1117 & * & 1184 & * & * & 1222 \\
\hline Pepperoni pizza (thin crust) & 1360 & 1485 & * & * & * & * & 1138 & * & * & 1326 \\
\hline \multicolumn{11}{|l|}{ Subway } \\
\hline 6" Veggie Delite & 561 & 594 & 561 & 582 & 653 & 598 & 561 & 556 & 607 & 586 \\
\hline
\end{tabular}

UAE, United Arab Emirates.

KFC Original Recipe Chicken in italics represent thigh pieces, others do not state type of piece.

${ }^{*}$ Data not available online or received following direct contact.

†Product is not available in this country.

chicken piece, which could explain some of the variation. The McDonald's Garden Side Salad in UAE was reported to contain $6.2 \mathrm{~g}$ total fat $/ 100 \mathrm{~g}$, whereas all countries except Canada $(1.3 \mathrm{~g}$ fat $/ 100 \mathrm{~g})$ had a negligible value.

\section{Discussion}

Our investigation of fast-food products demonstrates the wide variation in the serving size of similar products across different countries and reveals compositional differences in energy, total fat and saturated fat at both the category and individual product level. In some cases nutritional composition and serving size are additive, such that the energy and fat differences are greater when reviewed per serving rather than per $100 \mathrm{~g}$. Our results support and extend previous findings to provide a more comprehensive analysis of the nutrient content of fast foods ${ }^{(21)}$.

The disparity in energy, total fat and saturated fat contents within the same food category and particularly within the same individual product available in different countries clearly indicates that it is technically feasible for manufacturers to improve the nutritional quality of fast-food products. Manufacturers have a responsibility to act, or should expect to be challenged by public health groups, on the disparity in products between countries. While there may be issues of consumer expectations about the taste of a product, the experience of reformulation in some countries has shown it is possible to make large reductions in levels of sodium, sugar and fat over time if done in small steps ${ }^{(24)}$. Serving dressing or sauces as an option as opposed to a standard offer, and increased amounts of fruit and vegetables where possible, may be more feasible for manufacturers in some countries than product reformulation to reduce the levels of fat, sugar and energy. Similarly, standardising serving sizes towards the lower end of the international range will help to reduce consumption of energy, fat and saturated fat from fast foods as the greatest variations in our study were observed when comparisons were made per serving.

It is notable that there is substantial variation within a single food category, for example chicken or salads. In the case of larger serving sizes of a comparable product, the higher energy content may be evident to consumers but in categories such as salads with greater diversity it may be less clear. This highlights the importance of clear food labelling so consumers can make a more informed choice at the point of purchase.

Our review has some limitations, primarily relating to data collection and availability. The presented data do not purport to represent the entire fast-food market. However, the review provides a useful snapshot of the international variations in nutrient composition and serving size of foods often considered to be a standardised product. We have captured data as available on company websites and available to consumers and have assumed these data are accurate; however, we do note data were collected in 2012 and products may have been modified since. Product data collected reflect online availability at that time and as such may contain some seasonal items; data for McDonald's Japan included some Christmas varieties. Efforts were made to standardise data availability through the 3-month collection period between January and March, when there are generally fewer seasonal items on menus. As often the situation with data collection exercises, we could not have foreseen where data for nutrient content or serving size would be missing between brands and countries. Pizza Hut data were difficult to obtain in more than half our selected countries and data per $100 \mathrm{~g}$ or serving size were not available for all chains in China. Data on saturated fat content were not available for any Japanese chain, showing that chains opt to provide different information in 
different countries. Fast food and restaurant nutrition labelling has been exempt from food labelling laws until recently and is now starting to emerge as part of the legislation, which might explain some of the differences in the data availability between the countries. Product availability is shown in our data with the number of products reviewed varying substantially between longstanding fast-food markets of USA, Canada and the UK, compared with emerging markets in the Middle East countries and China. Where we have presented data for serving size, these are solely recommendations provided by manufacturers and although many items are single piece (such as burgers), there are some recommended for multiple servings that may be consumed as an individual serving. Additionally the data presented relate to the range of products on offer and do not reflect the pattern of purchasing of items, which may differ between countries.

The food environment is an important determinant of the choices made by individuals ${ }^{(25,26)}$. Given the continuing global rise in levels of obesity and its related diseases, there is a pressing need for global companies to consider the nutritional composition and serving sizes of the products they offer. Ensuring that the nutritional content in every country reflects the best that is possible anywhere in the world is an important step. It is hoped that responsible companies will want to ensure that progress made in some countries to reformulate should be matched worldwide and the current analysis will support the advocacy efforts of civil society to improve public health in countries where progress is slow. It also provides a baseline to assess secular trends in these products within each country over time.

\section{Acknowledgements}

Acknowledgements: The authors would like to acknowledge the work of the Global Food Monitoring Group for its involvement in generating the data collection protocol for fast foods, which was used to guide the method adopted in this work. Thanks are given to Ivonne Solis-Trapala of MRC Human Nutrition Research for providing statistical advice. Financial support: This work was supported by the UK Medical Research Council (programme number 53205). The funder had no role in the design, analysis or writing of this article. Conflict of interest: E.F., N.Z., L.E., E.D. and S.A.J. declare they have no conflict of interest and no competing interests. L.E. was an undergraduate placement student at MRC Human Nutrition Research during the time of this work and was responsible for collecting the nutritional information of foods. B.N. is the Chair of the Australian Division of World Action on Salt and Health, was a member of the Pepsico Global Scientific Advisory Board (2010 to 2012) and receives research funding from the Australian Food and Grocery Council as part of a National Health and Medical Research Council of Australia Partnership Grant (2010 to 2014). Authorship: S.A.J. and E.F. developed the concept of the paper. L.E. and N.Z. prepared the results. E.F. and
N.Z. wrote the first draft of the manuscript and all authors were involved in the writing and critical review of this paper. Ethics of human subject participation: Ethical approval was not required.

\section{Supplementary material}

To view supplementary material for this article, please visit http://dx.doi.org/10.1017/S1368980015000336

\section{References}

1. Pingali P (2007) Westernization of Asian diets and the transformation of food systems: implications for research and policy. Food Policy 32, 281-298.

2. Musaiger A (2004) Overweight and obesity in the Eastern Mediterranean Region: can we control it? East Mediterr Health J 10, 789-793.

3. Monteiro C (2009) Nutrition and health. The issue is not food, nor nutrients, so much as processing. Public Health Nutr 12, 729-731.

4. Jabs J \& Devine C (2006) Time scarcity and food choices: an overview. Appetite 47, 196-204.

5. Jaworowska A, Blackham T, Davies I et al. (2013) Nutritional challenges and health implications of takeaway and fast food. Nutr Rev 71, 310-318.

6. Fraser L, Clarke G, Cade J et al. (2012) Fast food and obesity: a spatial analysis in a large United Kingdom population of children aged 13-15. Am J Prev Med 42, e77-e85.

7. Cummins S, McKay L \& MacIntyre S (2005) McDonald's restaurants and neighborhood deprivation in Scotland and England. Am J Prev Med 29, 308-310.

8. Fraser L \& Edwards K (2010) The association between the geography of fast food outlets and childhood obesity rates in Leeds, UK. Health Place 16, 1124-1128.

9. Stark J, Neckerman K, Lovasi G et al. (2013) Neighbourhood food environments and body mass index among New York City adults. J Epidemiol Community Health 67, 736-742.

10. Shier V, An R \& Sturm R (2012) Is there a robust relationship between neighbourhood food environment and childhood obesity in the USA? Public Health 126, 723-730.

11. Xu H, Short S \& Liu T (2013) Dynamic relations between fast-food restaurant and body weight status: a longitudinal and multilevel analysis of Chinese adults. I Epidemiol Community Health 67, 271-279.

12. Pereira M, Kartashov A, Ebbeling C et al. (2005) Fast-food habits, weight gain, and insulin resistance (the CARDIA study): 15-year prospective analysis. Lancet 365, 36-42.

13. Bowman S \& Vinyard B (2004) Fast food consumption of US adults: impact on energy and nutrient intakes and overweight status. J Am Coll Nutr 23, 163-168.

14. Smith K, McNaughton S, Gall S et al. (2009) Takeaway food consumption and its associations with diet quality and abdominal obesity: a cross-sectional study of young adults. Int J Behav Nutr Phys Act 6, 29.

15. French S, Harnack L \& Jeffery R (2000) Fast food restaurant use among women in the Pound of Prevention study: dietary, behavioral and demographic correlates. Int $J$ Obes Relat Metab Disord 24, 1353-1359.

16. Ball K, Brown W \& Crawford D (2003) Who does not gain weight? Prevalence and predictors of weight maintenance in young women. Int J Obes Relat Metab Disord 26, 1570-1578.

17. Prentice A \& Jebb S (2003) Fast foods, energy density and obesity: a possible mechanistic link. Obes Rev 4, 187-194.

18. Close R \& Schoeller D (2006) The financial reality of overeating. J Am Coll Nutr 25, 203-209. 
19. Stender S, Dyerberg J \& Astrup A (2007) Fast food: unfriendly and unhealthy. Int J Obes (Lond) 31, 887-890.

20. Dunford E, Webster J, Barzi F et al. (2010) Nutrient content of products served by leading Australian fast food chains. Appetite 55, 484-489.

21. Dunford E, Webster J, Woodward M et al. (2012) The variability of reported salt levels in fast foods across six countries: opportunities for salt reduction. CMAJ 184, 1023-1028.

22. Young L \& Nestle M (2007) Portion sizes and obesity: responses of fast-food companies. J Public Health Policy 28, 238-248.
23. Food Monitoring Group (2012) International collaborative project to compare and track the nutritional composition of fast foods. BMC Public Health 12, 559.

24. Buttriss J (2013) Food reformulation: the challenges to the food industry. Proc Nutr Soc 72, 61-69.

25. Story M, Kaphingst K, Robinson-O'Brien R et al. (2008) Creating healthy food and eating environments: policy and environmental approaches. Annu Rev Public Health 29, 253-272.

26. Glanz K, Sallis J, Saelens B et al. (2005) Healthy nutrition environments: concepts and measures. Am J Health Promot 19, 330-333. 